\title{
A single dose of fentanyl and midazolam prior to Cesarean section have no adverse neontal effects
}

\author{
[Une seule dose de fentanyl et de midazolam administrée avant la césarienne n'a \\ pas d'effet néonatal]
}

Michael A. Frölich MD, ${ }^{\star}$ David J. Burchfield MD, † Tammy Y. Euliano MD, $\ddagger$ Donald Caton MD

Purpose: Analgesia and sedation, routinely used as adjunct medications for regional anesthesia, are rarely used in the pregnant patient because of concerns about adverse neonatal effects. In an effort to obtain more information about maternal analgesia and sedation we studied neonatal and maternal effects of iv fentanyl and midazolam prior to spinal anesthesia for elective Cesarean section.

Methods: In this double-blinded, randomized, placebo-controlled trial, 60 healthy women received either a combination of I $\mu \mathrm{g} \cdot \mathrm{kg}^{-1}$ fentanyl and $0.02 \mathrm{mg} \cdot \mathrm{kg}^{-1}$ midazolam intravenously or an equal volume of iv saline at the time of their skin preparation for a bupivacaine spinal anesthetic. Sample size was based on a non-parametric power analysis (power $>0.80$ and alpha $=0.05$ ) for clinically important differences in Apgar scores. Fetal outcome measures included Apgar scores, continuous pulse oximetry for three hours, and neurobehavioural scores. Maternal outcomes included catecholamine levels, and recall of anesthesia and delivery.

Results: There were no between-group differences of neonatal outcome variables (Apgar score, neurobehavioural scores, continuous oxygen saturation). Mothers in both groups showed no difference in their ability to recall the birth of their babies.

Conclusions: Maternal analgesia and sedation with fentanyl (I $\left.\mu \mathrm{g} \cdot \mathrm{kg}^{-1}\right)$ and midazolam $\left(0.02 \mathrm{mg} \cdot \mathrm{kg}^{-1}\right)$ immediately prior to spinal anesthesia is not associated with adverse neonatal effects.
Objectif: L'analgésie et la sédation, complément habituel à l'anesthésie régionale, sont rarement utilisées chez la femme enceinte parce qu'on craint les effets néonatals indésirables. Pour en savoir davantage sur l'analgésie et la sédation de la mère, nous avons étudié les effets sur la mère et l'enfant du fentanyl et du midazolam iv administrés avant la rachianesthésie pour césarienne.

Méthode : Pour l'étude randomisée, à double insu et contrôlée contre placebo, 60 femmes en santé ont reçu une combinaison intraveineuse de I $\mu \mathrm{g} \cdot \mathrm{kg}^{-1}$ de fentanyl et $0,02 \mathrm{mg} \cdot \mathrm{kg}^{-1}$ de midazolam ou un volume égal de solution saline iv au moment de préparer à la rachianesthésie avec bupivacaïne. La taille de l'échantillon reposait sur une analyse de puissance non paramétrique (puissance $>0,80$ et alpha $=0,05$ ) pour des différences cliniquement importantes d'indices d'Apgar. Les mesures de l'évolution du fœtus comprenaient l'indice d'Apgar, la sphygmo-oxymétrie continue pendant trois heures et les scores neurocomportementaux. L'évaluation de la mère incluait les niveaux de catécholamine et la présence de souvenir de l'anesthésie et de l'accouchement.

Résultats : Il n'y a pas eu de différence intergroupe des variables mesurées chez le nouveau-né (indice d'Apgar, comportement neurologique, mesure continue de la saturation en oxygène). Les mères des deux groupes ont montré la même capacité à se rappeler la naissance de leurs enfants.

Conclusion : L'analgésie et la sédation maternelles avec du fentanyl (I $\left.\mu \mathrm{g} \cdot \mathrm{kg}^{-1}\right)$ et du midazolam $\left(0,02 \mathrm{mg} \cdot \mathrm{kg}^{-1}\right)$ administrées immédiatement avant la rachianesthésie ne sont pas associées à des effets néonatals indésirables.

From the Department of Anesthesiology, ${ }^{*}$ University of Alabama at Birmingham, Birmingham, Alabama; and the Departments of Pediatrics, $†$ and Anesthesiology, , University of Florida, Gainesville, Florida, USA.

Address correspondence to: Dr. Michael Frölich, Department of Anesthesiology, University of Alabama at Birmingham, 619 South 19th

Street, Birmingham, AL 35249-6810, USA. Phone: 205-975-0145; Fax: 205-975-5963; E-mail: froelich@uab.edu

Support: This project was supported in part by funds from the National Institute of Health GCRC M01-RR00082 at the University of Florida.

Accepted for publication July 5, 2005.

Revision accepted August 29, 2005. 
$\mathrm{T}$ HE study of drugs used during pregnancy is one of the most neglected areas in the field of clinical pharmacology and drug research. ${ }^{1}$ Considering the amount of pharmacological research in the general population, data available on drug biodisposition and effect of orally and intravenously administered drugs in the pregnant patient are scarce, fragmentary and frequently contradictory. The anesthesia literature on drug effects in pregnancy, although more comprehensive, focuses on the pharmacology of epidural or spinally administered opioids and local anesthetics, rather than adjuvant iv medication. Few reports discuss the iv administration of midazolam during pregnancy without providing much information about its use close to delivery. ${ }^{2-4}$ Because pregnant women may benefit from iv analgesia and sedation in preparation for medical or surgical procedures, we designed a study to compare maternal and neonatal effects of two common anesthetic drugs, midazolam and fentanyl when compared to placebo (saline control) in pregnant women. Both drugs are routinely used as premedication for a significant portion of surgical procedures performed annually, an estimated 42 million in the United States of America alone. ${ }^{5}$ As premedication for regional anesthesia in pregnancy, $i v$ analgesia and sedation is the exception rather than the rule. Although benzodiazepines and opioids have stood the test of time, physicians are still hesitant to administer them to term pregnant patients because information on transplacental pharmacology and fetal safety is scarce. ${ }^{6}$ To provide more information regarding procedural premedication in term pregnancy, we tested whether a small $i v$ dose of fentanyl and midazolam in combination was associated with adverse neonatal effects or maternal amnesia. We hypothesized that premedication as used in this study does not have a demonstrable clinical effect on the neonate.

\section{Methods \\ Design and sample size}

This study was a randomized, prospective, placebocontrolled clinical trial. Our power analysis was based on Apgar scores. We estimated that a sample size of 49 subjects would be required to detect a $6 \%$ difference in normal five-minute Apgar scores (8 and 9) with 80\% power, and an alpha error of 0.05 . For this analysis normal Apgar scores were compared to Apgar scores ranging from 4 to 7 , and less than 4 (Chi-square, $\mathrm{DF}=5$ ). We recruited 60 patients to compensate for incomplete data. The Institutional Review Board of the Health Science Center and the Review Board of the General Clinical Research Center of the University of Florida approved this study.

\section{Recruitment}

Study subjects were patients scheduled for an elective Cesarean section. We introduced this study and obtained written informed consent from patients after they had been admitted to the preoperative area on the day of their scheduled Cesarean section. After being informed of a new study participant, our satellite pharmacy prepared the study medication (either midazolam and fentanyl or an equal volume of normal saline) according to a concealed randomization list. Exclusion criteria were significant pre-existing maternal or fetal medical problems, chronic pain, insulin-dependent diabetes mellitus, hypertensive disease of pregnancy and a body mass index $>39 \mathrm{~kg} \cdot \mathrm{m}^{2}$ (morbid obesity). Typical indications for the scheduled Cesarean section were a history of prior Cesarean delivery or fetal malpresentation.

\section{Anesthesia}

Patients underwent spinal anesthesia with $12 \mathrm{mg}$ hyperbaric bupivacaine, $10 \mu \mathrm{g}$ fentanyl and $300 \mu \mathrm{g}$ preservative-free morphine in the sitting position. Mothers received oxygen at a rate of $2 \mathrm{~L} \cdot \mathrm{min}^{-1}$ via nasal cannula. Maternal monitoring included noninvasive blood pressure measurement, pulse oximetry and electrocardiography. Fetal heart rate was recorded until mothers were placed supine.

\section{Study drug administration and blinding}

Study drugs were prepared by the operating room satellite pharmacy according to the randomization protocol, and consisted of either a mixture of fentanyl $\left(1 \mu \mathrm{g} \cdot \mathrm{kg}^{-1}\right)$ and midazolam $\left(0.02 \mathrm{mg} \cdot \mathrm{kg}^{-1}\right)$ or an equal volume of normal saline (placebo). No individual other than the pharmacist preparing the study medication had access to the randomization protocol. Study drugs were administered at the time of skin preparation for the spinal anesthesia. The time interval from drug administration to delivery was recorded.

\section{Fetal outcome measures}

The pediatrician on duty recorded fetal Apgar scores at one and five minutes. Arterial and venous cord blood was collected to assess the fetal acid-base status immediately after the umbilical cord was clamped. One of two study nurses with expertise in neonatal medicine recorded fetal pulse oximetry for three hours and obtained two newborn neurobehavioural scores three hours after birth; the neurologic and adaptive capacity score (NACS) and the early neonatal neurobehavioural scale (ENNS). Fetal oxygen saturation was recorded manually every ten to 15 min and continuously, using a Nellcor N-595 pulsoximeter, for three hours after 
birth. The Score ${ }^{\mathrm{TM}}$ Analysis Software (version 1.la, Mallinckrodt Inc., St. Louis, MO, USA) was used for analysis of oxygen saturation data. Within the $\mathrm{Score}^{\mathrm{TM}}$ Analysis program, criteria for the detection of desaturation episodes are customizable. We used two criteria for the electronic identification of desaturation episodes: (a) pulse oximetry reading less than $90 \%$ for more than ten seconds or (b) pulse oximetry reading less than $95 \%$ for more than ten seconds. Presumed desaturation episodes associated with a lost fetal heart rate tracing were identified as electronic artefacts and discarded. No supplemental oxygen was administered to neonates during the three-hour observation period.

\section{Maternal outcome measures}

To assess the potential effect of analgesia and sedation on the maternal stress response, we measured catecholamine plasma levels at the time of delivery using high performance liquid chromatography (HPLC). Venous blood samples were separated in a refrigerated centrifuge, frozen immediately and sent on dry ice individually for analysis at the Quest Diagnostics Nichols Institute. The HPLC assay used to analyze samples had greater than $98 \%$ reliability; detection limits were $<20 \mathrm{pg} \cdot \mathrm{mL}^{-1}$ for both epinephrine and norepinephrine. Mothers were also asked questions to assess recall of their birth and anesthesia while in the recovery room. The three questions asked were: "how do you remember the placement of your spinal anesthetic?", "how do you remember the birth of your child?" and "did you find the medication which was given to help you relax helpful?"

\section{Statistical analysis}

Continuous data, such as cord $\mathrm{pH}$, are summarized as means and standard deviation, and were compared between the two groups with a two-sided, independent-sample t test. Ordinal data are summarized as median and range and analyzed with the Chi-square test or Mann-Whitney test if assumptions for the Chisquare analysis were violated. Frequency responses to questions about maternal recall were compared using the Chi-square test. To meet the Cochrane criterion for Chi-square tests, counts for desaturation episodes were collapsed into five levels. Multiple comparisons of blood gas values were performed with the Bonferroni $t$ test. A probability level $<0.05$ was considered significant.

\section{Results}

Subject characteristics

Women did not differ with respect to their weight, height or age (Table I).
TABLE I Subject characteristics

\begin{tabular}{lll}
\hline & Placebo & Midazolam / Fentanyl \\
\hline Height $(\mathrm{cm})$ & $159.3(16.3)$ & $163.1(7.4)$ \\
Weight $(\mathrm{kg})$ & $93.5(18.4)$ & $87.5(23.8)$ \\
Age $(\mathrm{yr})$ & $27.2(6.4)$ & $27.4(6.1)$ \\
\hline
\end{tabular}

Subject characteristics are displayed in SI units. There are no significant group differences $(P<0.05$, paired t test).

\section{Fetal outcome measures}

The results of fetal outcomes are displayed in Table II. There were no significant differences in either oneminute or five-minute cord gas values, ENNS and NACS scores. None of the neonates showed clinically significant oxygen desaturation. Eight neonates, four neonates from the placebo and four from the fentanyl/midazolam group, were admitted to the level III nursery for temporary observation (one-on-one nursing care). Clinical details regarding these neonatal intensive care unit (NICU) admissions is provided in Table III. These infants were included in the analysis.

\section{Maternal outcome measures}

We did not observe a difference with respect to maternal birth recall, whereas more mothers in the fentanyl/midazolam group perceived their anesthesia as being pleasant and the study medication as helpful (Figure 1). Maternal catecholamine levels were similar in the two groups (Figure 2). One participant received an unintended high dose of $4 \mathrm{mg}$ of midazolam and $200 \mu \mathrm{g}$ of fentanyl. This subject was included in the analysis and individual data are provided in Table III. Another participant required supplemental iv anesthesia because of inadequate spinal anesthesia. Because of the added maternal stress and increased iv narcotic administration during the procedure, the study protocol was discontinued and this subject could not enter the analysis.

\section{Discussion}

The use of fentanyl and midazolam as a method of labour pain relief has been the subject of many studies. ${ }^{7,8}$ Many opioids are used routinely for labour pain relief if neuraxial analgesia is relatively contraindicated such as in the thrombocytopenic patient. ${ }^{9}$ The use of opioids and/or benzodiazepines as adjunct anesthetic medication for operative procedures during pregnancy is rare, but has been described as part of general anesthesia. ${ }^{10,11}$ Reports have also documented the successful use of iv sedation during pregnancy and the use of $i v$ narcotics during labour as an alternative to 
TABLE II Neonatal data

\begin{tabular}{|c|c|c|c|c|}
\hline & & Placebo & Drug & P-palue \\
\hline Apgar & $\begin{array}{l}\text { One-minute } \\
\text { Five-minute }\end{array}$ & $\begin{array}{l}9[0-9] \\
9[8-9]\end{array}$ & $\begin{array}{l}9[2-9] \\
9[7-9]\end{array}$ & $\begin{array}{l}0.66^{*} \\
0.97^{*}\end{array}$ \\
\hline$A C B G$ & $\begin{array}{l}\mathrm{pH} \\
\mathrm{CO}_{2} \\
\mathrm{pO}_{2} \\
\mathrm{HCO}_{3} \\
\text { Base deficit }\end{array}$ & $\begin{array}{l}7.23[0.10] \\
60.08[11.55] \\
16.52[5.25] \\
23.64[2.33] \\
4.85[4.60]\end{array}$ & $\begin{array}{l}7.26[0.04] \\
54.31[5.79] \\
17.65[4.88] \\
23.7[2.32] \\
3.65[2.35]\end{array}$ & $\begin{array}{l}0.08 \dagger \\
0.01 \dagger \\
0.76 \dagger \\
0.98 \dagger \\
0.21 \dagger\end{array}$ \\
\hline$V C B G$ & $\begin{array}{l}\mathrm{pH} \\
\mathrm{CO}_{2} \\
\mathrm{pO}_{2} \\
\mathrm{HCO}_{3} \\
\text { Base deficit }\end{array}$ & $\begin{array}{l}7.28[0.10] \\
49.41[8.94] \\
24.39[5.26] \\
22.46[2.59] \\
4.33[4.25]\end{array}$ & $\begin{array}{l}7.32[0.04] \\
47.14[4.88] \\
27.88[6.46] \\
23.54[1.48] \\
2.39[1.40]\end{array}$ & $\begin{array}{l}0.08 \dagger \\
0.17 \dagger \\
0.03 \dagger \\
0.08 \dagger \\
0.04 \dagger\end{array}$ \\
\hline ENNS & $\begin{array}{l}\text { Pin prick } \\
\text { Tone } \\
\text { Rooting } \\
\text { Sucking } \\
\text { Moro response } \\
\text { Reaction to light } \\
\text { Response to sound } \\
\text { Placing } \\
\text { Alertness } \\
\text { General }\end{array}$ & $\begin{array}{l}3[1-3] \\
8[7-10] \\
2[0-2] \\
2[0-3] \\
2[0-3] \\
2[1-3] \\
2[1-3] \\
2[1-3] \\
1[1-3] \\
1[0-1]\end{array}$ & $\begin{array}{l}3[1-3] \\
7[4-10] \\
2[1-3] \\
2[1-3] \\
2[1-3] \\
2[1-3] \\
1[1-3] \\
2[1-3] \\
1[1-3] \\
1[0-1]\end{array}$ & $\begin{array}{l}0.84^{*} \\
0.54^{*} \\
0.84^{*} \\
0.87^{*} \\
0.55^{*} \\
0.6 \text { * } \\
0.58^{*} \\
0.29^{*} \\
0.51 \text { * } \\
0.98^{*}\end{array}$ \\
\hline$N A C S$ & & $32.7(5.2)$ & $33.6(3.7)$ & $0.44^{*}$ \\
\hline Desat. & $\begin{array}{l}\mathrm{SpO}_{2}<95 \% \\
\mathrm{SpO}_{2}<90 \%\end{array}$ & $\begin{array}{l}12[0-60] \\
4[0-15]\end{array}$ & $\begin{array}{l}15[0-34] \\
4[0-14]\end{array}$ & $\begin{array}{l}0.2^{*} \\
0.43^{*}\end{array}$ \\
\hline
\end{tabular}

$\mathrm{ACBG}=$ arterial cord blood gas; $\mathrm{VCBG}=$ venous cord blood gas. EENS = early neonatal neurobehavioural scale; NACS = neurologic and adaptive capacity score. * Not significant at -level of 0.05 ; †not significant at Bonferroni adjusted $\alpha-$ level of 0.005 . Neonatal data are summarized as median and range is denoted in square brackets or mean and standard deviation round brackets as appropriate. The statistical test used to compare groups was the Wilcoxon rank-sum test for non-normally distributed data and the paired t test for normal data. Adjustments for multiple comparisons were not performed. Alpha values are Bonferroni-adjusted for the comparisons of the multiple, partially related blood gas values.

epidural analgesia, but midazolam and fentanyl as premedication for spinal anesthesia have not been studied prospectively. ${ }^{12-14}$ Premedication to facilitate neuraxial blockade remains the rare exception in pregnant patients, based on concerns about potential untoward effects of fetal drug exposure. The most worrisome adverse fetal effects are over sedation, decreased motor tone, and respiratory compromise. In fact, in the 1960's several case reports described decreased motor tone in infants born to mothers who had been treated with diazepam during their pregnancy. ${ }^{15,16}$ Another reason for the relative infrequent use of benzodiazepines during pregnancy is probably related to their putative association with facial malformations in animals when given during the teratogenic period of pregnancy, although, in a recent review, the alleged association of benzodiazepine use during pregnancy with facial malformations has been completely dismissed. ${ }^{17,18}$ Therefore, women in some cases may endure a great deal of anxiety and discomfort when undergoing placement of a spinal or epidural block for Cesarean delivery.

In an effort to address these concerns, we decided to study the effect of a single bolus dose of midazolam and fentanyl prior to elective Cesarean section. We chose a single dose based on weight, rather than multiple doses, to ensure uniform treatment of patients in both study arms. We also chose a concentration likely to achieve a clinical effect without causing excessive maternal sedation or respiratory compromise. We 
TABLE III Subjects admitted to level III nursery

\begin{tabular}{|c|c|}
\hline Reason for intensive care unit admission & Randomization group \\
\hline Respiratory (“grunting”) & Midazolam \& fentanyl \\
\hline Respiratory (“grunting”) & Placebo \\
\hline Metabolic (hypoglycemia) & Midazolam \& fentanyl \\
\hline Respiratory ("grunting") & Midazolam \& fentanyl \\
\hline Metabolic (hypoglycemia) & Placebo \\
\hline Respiratory ("tachypnea") & Placebo \\
\hline $\begin{array}{l}\text { Respiratory depression not responsive } \\
\text { to naloxone }\end{array}$ & Placebo \\
\hline $\begin{array}{l}\text { Medication error ( } 200 \mu \mathrm{g} \text { fentanyl and } \\
4 \mathrm{mg} \text { midazolam }) \text { Maternal data: body } \\
\text { mass index: } 37 \mathrm{~kg} \cdot \mathrm{m}^{2} \text {, birth recall: } \\
\text { pleasant. }\end{array}$ & Midazolam \& fentanyl \\
\hline $\begin{array}{l}\text { Fetal data: umbilical vein } \mathrm{pH}=7.34 \\
\text { APGAR }=9 / 9\end{array}$ & \\
\hline \multicolumn{2}{|c|}{$\begin{array}{l}\text { This table describes all unanticipated neonatal intensive care unit } \\
\text { III admissions involving study patients. Each of these admissions } \\
\text { was promptly reported to the Institutional Review Board and } \\
\text { additional precaution implemented as needed. These events, with } \\
\text { one exception, were considered unlikely to be related to study } \\
\text { interventions. }\end{array}$} \\
\hline
\end{tabular}

realize however, that individual responses to a single weight-based bolus dose may vary considerably, and that in clinical practice one may prefer to titrate iv drugs to effect. Thus, the findings of our study may not be applicable if higher or repeated doses of iv analgesia and sedation are chosen.

Apgar scores are routinely measured because of the clear physiological correlation of this scoring system to characterize neonatal well being. ${ }^{19}$ Our sample size was therefore based on this parameter. We also recorded umbilical cord blood gas values and noted no significant difference. The reliability of either Apgar scores or fetal cord gas values to detect respiratory depression and hypoxia has been questioned. ${ }^{20,21}$ Therefore, we decided to record and analyze pulse oximetry in the neonate as well. We noted that the analysis of continuous pulse oximetry revealed a surprisingly high median number of 3.5 and 4 desaturation episodes (oxygen saturation $<90 \%$ for more than ten seconds) in the study groups. However, these episodes went unnoticed by the clinical observer (research nurse). We also recorded and reported to the Institutional Review Board on a case-by-case basis whenever a newborn was assigned to the level III (neonatal intensive care) nursery for closer observation, even if assigned for a brief time period. Given the healthy study population, the NICU admission rate may appear high, but is consistent with our overall conservative NICU admission policy followed by the pediatric house officer called to evaluate term new-

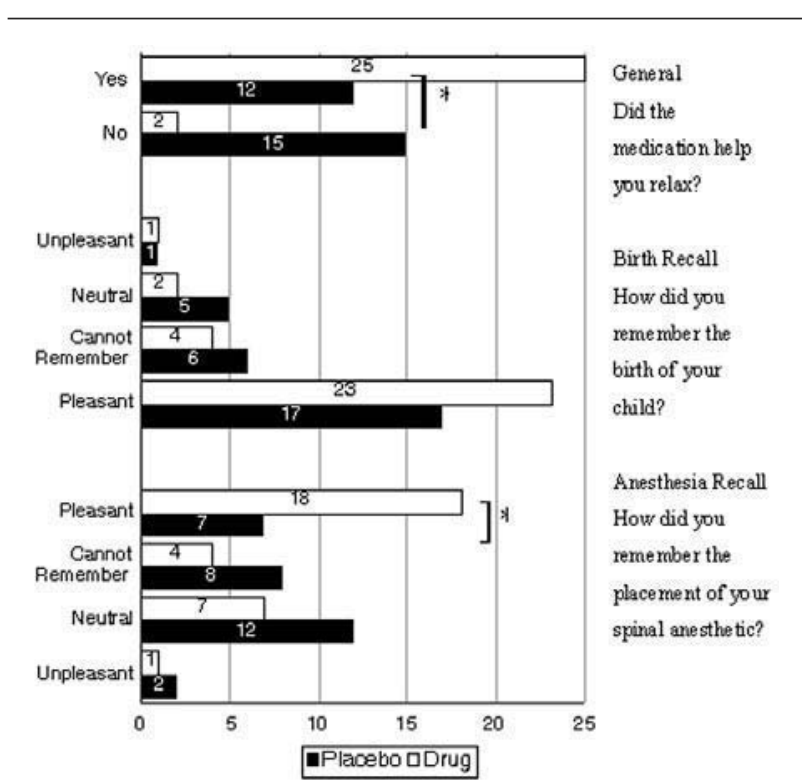

FIGURE 1 Questions about recall were asked in the recovery room prior to discharge to the postpartum floor. The categories assessed were the general perception of premedication, recall of birth and recall of spinal anesthetic placement. The label "neutral" substitutes the response "something I can deal with" for the "anesthesia recall" question and "concerned with other things" for the "birth recall" question. Significant differences within each group are marked with an asterisk (Pearson Chi-square, $P<0.05$ ).

borns. The apparent non-reassuring clinical condition of some neonates in both of our study groups reflects the physiologic instability during this transition period of neonatal life. ${ }^{22}$

Other fetal outcome measures used were the NACS and the ENNS. ${ }^{23,24}$ These two neurobehavioural scales are not universally accepted, but both have been used to assess the potential effects of neonatal drug exposure. ${ }^{25,26}$ Both tests are designed to differentiate drug-induced neonatal depression from depression secondary to asphyxia, and were found to have good interobserver reliability. ${ }^{23}$ While the ENNS concentrates on the infant's habituation ability, the NACS emphasizes motor tone as a key indicator of druginduced abnormal behaviour. The mean NACS in our study (33 in both groups, Table II) are somewhat lower than what was originally proposed for normal newborns (35-40). These scores probably reflect the individual application of the scoring system by the two blinded pediatric research nurses trained in biophysical evaluation of newborns, rather than an overall abnormal group of infants. This finding gives more sup- 

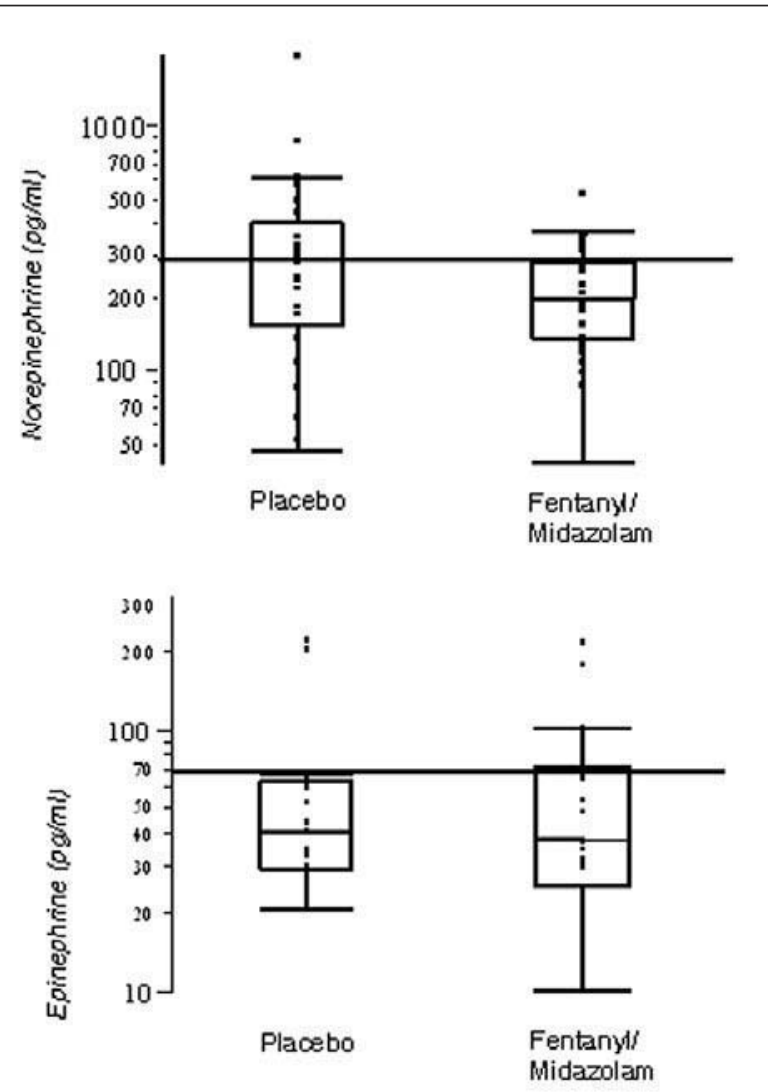

FIGURE 2 Box plots show concentrations of catecholamines on a logarithmic scale. Boxes mark the $25^{\text {th }}, 50^{\text {th }}$ (median) and $75^{\text {th }}$ percentile, whiskers extend from the $5^{\text {th }}$ to the $95^{\text {th }}$ percentile, individual data points are represented by dots. The two study groups were similar with respect to maternal norepinephrine and epinephrine concentrations (Wilcoxon rank-sum test).

port to the view of Brockhurst and Littleford, which indicate its poor reliability in obstetric anesthesia research. ${ }^{25}$ Because of these concerns, we use a combination of these neonatal measures to make predictions about neonatal drug effects.

As part of this study, we also assessed maternal recall of anesthesia and birth. This topic is relevant since the ability of the mother to experience the birth of her baby during Cesarean delivery is one of the foremost rewards of regional anesthesia. Active recall of the spinal anesthetic placement on the other hand is not desirable by most patients. We asked three simple questions while patients were still in the recovery room to address recall. Maternal responses demonstrate that premedication as used in our study is not associated with maternal amnesia and that mothers in the premedication group have a more pleasant memory of the spinal anesthetic administration. The main intent of our questions was to assess maternal amnesia in a concrete fashion. We therefore inquired about specific events, the placement of the spinal anesthetic and the actual birth event. More patients in both groups had a pleasant recall of the birth, an event with positive emotional content. More patients in each group had neutral responses when asked about the anesthetic, most likely because this event, unlike the birth is associated with anxiety in most patients. We also note with interest that several participants in the placebo group did not remember birth or anesthesia. This is an important observation as it reminds us that factors other than medication such as the patient's level of interest in experiencing the birth, the patient's level of anxiety and other situational factors may have an impact on a mother's ability to recall intraoperative events. We did not repeat our question at a later time and one should consider that the effect on memory at later time points may be different.

One approach to assess the maternal response to stress is the quantification of plasma catecholamine concentrations. Maternal catecholamine levels have been proposed as indicators for the maternal stress response associated with labour and delivery by Shnider et al. ${ }^{27}$ We compared plasma epinephrine and norepinephrine concentrations between the sedation and placebo groups and observed the results to be similar. This negative finding may be explained by the attenuating effect of regional anesthesia on the excretion of circulating catecholamines noted by Shnider $e t$ al. ${ }^{27}$ a factor that was present in both study groups. The effect of $i v$ analgesia and sedation may, by comparison, have a very small or no impact on circulating catecholamines.

The results of this double-blinded, placebo-controlled study of maternal premedication illustrates that a combination of a modest dose of fentanyl and midazolam improves patient comfort, without inducing adverse affects in the newborn, or maternal amnesia during the peripartum period. However, we do caution that fetal or maternal effects may develop if large or repeated doses of fentanyl and midazolam are given, or the iv administration is closer to delivery and that continuous cardiorespiratory monitoring is essential.

\section{References \\ 1 National Institute of Child Health and Human Development (NICHD) Request for Application.}


Obstetric-Fetal Pharmacology Research Units RFA: HD-03-017. July 29, 2003. National Institutes of Health (http://grants2.nih.gov/grants/guide/rfafiles/FRA-HD-03-017.htm]).

2 Camann W, Cohen MB, Ostheimer GW. Is midazolam desirable for sedation in parturients? (Letter). Anesthesiology 1986; 65: 441.

3 Seidman SF, Marx GF. Midazolam in obstetric anesthesia (Letter). Anesthesiology 1987; 67: 443-4.

4 Wilson CM, Dundee JW, Moore J, Howard PJ, Collier PS. A comparison of the early pharmacokinetics of midazolam in pregnant and nonpregnant women. Anaesthesia 1987; 42: 1057-62.

5 DeFrances CJ, Hall MJ. 2002 National Hospital Discharge Survey. Adv Data 2004; 21 : 1-29.

6 Wakefield ML. Systemic analgesia: parenteral and inhalation agents. In: Chestnut $\mathrm{D}$ (Ed.). Obstetric Anesthesia: Principles and Practice. Philadelphia: Elsevier Mosby; 2004: 311-23.

7 Mattingly JE, D'Alessio J, Ramanathan J. Effects of obstetric analgesics and anesthetics on the neonate. A review. Paediatr Drugs 2003; 5: 615-27.

8 Bricker L, Lavender T. Parenteral opioids for labor pain relief: a systematic review. Am J Obstet Gynecol 2002; 186: S94-109.

9 Rosaeg OP, Kitts JB, Koren G, Byford LJ. Maternal and fetal effects of intravenous patient-controlled fentanyl analgesia during labour in a thrombocytopenic parturient. Can J Anaesth 1992; 39: 277-81.

10 Rout CC, Rocke DA. Effects of alfentanil and fentanyl on induction of anaesthesia in patients with severe pregnancy-induced hypertension. Br J Anaesth 1990; 65: 468-74.

11 Ravlo O, Carl P, Crawford ME, Bach V, Mikkelsen $B O$, Nielsen HK. A randomized comparison between midazolam and thiopental for elective cesarean section anesthesia: II. Neonates. Anesth Analg 1989; 68: 234-7.

12 Cheng YJ, Wang YP, Fan SZ, Liu CC. Intravenous infusion of low dose propofol for conscious sedation in cesarean section before spinal anesthesia. Acta Anaesthesiol Sin 1997; 35:79-84; Erratum 1997; 35: 191.

13 Rayburn W, Ratbke A, Leuschen MP, Chleborad J, Weidner W. Fentanyl citrate analgesia during labor. Am J Obstet Gynecol 1989; 161: 202-8.

14 Atkinson BD, Truitt LJ, Rayburn WF, Turnbull GL, Christensen HD, Wlodaver A. Double-blind comparison of intravenous butorphanol (Stadol) and fentanyl (Sublimaze) for analgesia during labor. Am J Obstet Gynecol 1994; 171: 993-8.

15 Gillberg C. "Floppy infant syndrome" and maternal diazepam (Letter). Lancet 1977; 2: 244.
16 Haram K. "Floppy infant syndrome" and maternal diazepam (Letter). Lancet 1977; 2: 612-3.

17 Dolovich LR, Addis A, Vaillancourt JM, Power JD, Koren $G$, Einarson TR. Benzodiazepine use in pregnancy and major malformations or oral cleft: metaanalysis of cohort and case-control studies. BMJ 1998; 317: 839-43.

18 Koren G, Pastuszak A, Ito S. Drugs in pregnancy. N Engl J Med 1998; 338: 1128-37.

19 Hoffmann AL, Hjortdal JO, Secher NJ, Weile B. The relationship between Apgar score, umbilical artery $\mathrm{pH}$ and operative delivery for fetal distress in 2778 infants born at term. Eur J Obstet Gynecol Reprod Biol 1990; 38: 97-101.

20 Socol ML, Garcia PM, Riter S. Depressed Apgar scores, acid-base status, and neurologic outcome. Am J Obstet Gynecol 1994; 170: 991-9.

21 Kubnert BR, Linn PL, Kubnert PM. Obstetric medication and neonatal behavior. Current controversies. Clin Perinatol 1985; 12: 423-40.

22 Benlabed M, Dreizzen E, Ecoffey C, Escourrou P, Migdal $M$, Gaultier C. Neonatal patterns of breathing after cesarean section with or without epidural fentanyl. Anesthesiology 1990; 73: 1110-3.

23 Amiel-Tison C, Barrier G, Shnider SM, Levinson $G$, Hughes SC, Stefani SJ. The neonatal neurologic and adaptive capacity score (NACS) (Letter). Anesthesiology 1982; 56: 492-3.

24 Scanlon JW, Ostheimer GW, Lurie AO, Brown WU Jr, Weiss JB, Alper $M H$. Neurobehavioral responses and drug concentrations in newborns after maternal epidural anesthesia with bupivacaine. Anesthesiology 1976; 45: 400-5.

25 Brockhurst NJ, Littleford JA, Halpern SH. The Neurologic and Adaptive Capacity Score. A systematic review of its use in obstetric anesthesia research. Anesthesiology 2000; 92: 237-46.

26 Camann W, Brazelton TB. Use and abuse of neonatal neurobehavioral testing (Editorial). Anesthesiology 2000; 92: 3-5.

27 Shnider SM, Abboud TK, Artal R, Henriksen EH, Stefani SJ, Levinson G. Maternal catecholamines decrease during labor after lumbar epidural anesthesia. Am J Obstet Gynecol 1983; 147: 13-5. 